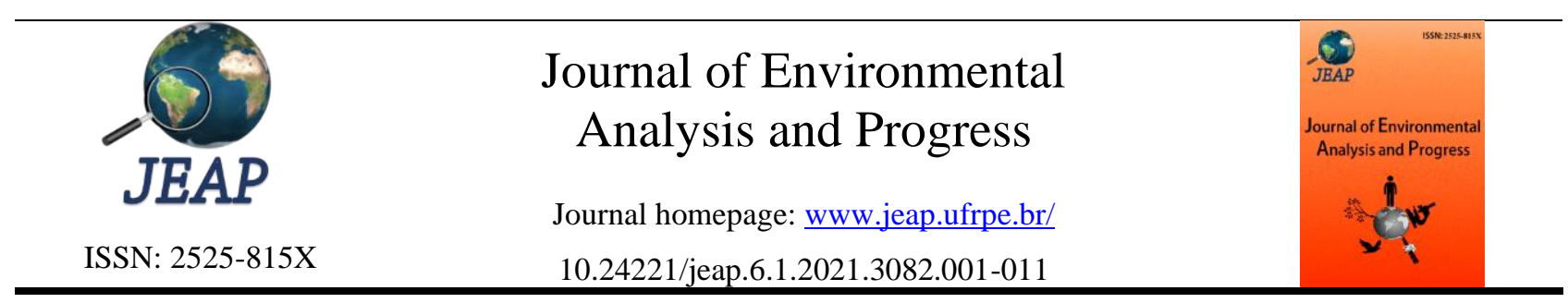

\title{
Cultura organizacional como fator determinante para a adoção da Produção Mais Limpa
}

\section{Organizational culture as a determining factor for the adoption of Cleaner Production}

\author{
Maria de Fátima da Silva ${ }^{\mathrm{a}}$, Almir Silveira Menelau ${ }^{\mathrm{a}}$ \\ ${ }^{a}$ Universidade Federal Rural de Pernambuco-UFRPE. Rua Dom Manoel de Medeiros, S/N, Campus Recife, Bloco C $1^{\circ}$

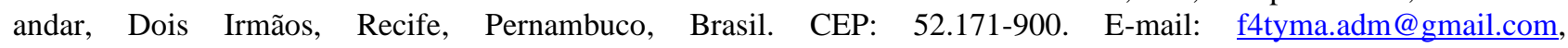 \\ almirmenelau@yahoo.com.br.
}

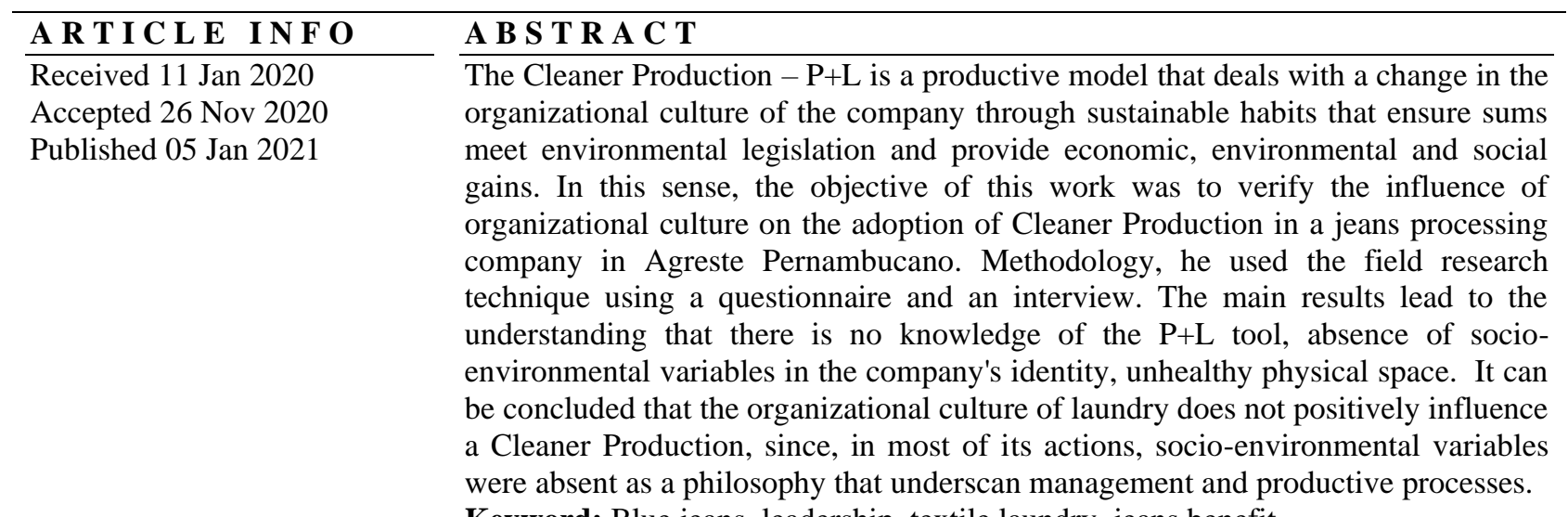

Keyword: Blue jeans, leadership, textile laundry, jeans benefit.

\section{R E S U M O}

A Produção Mais Limpa - P+L é um modelo produtivo que versa sobre uma mudança na cultura organizacional da empresa através de hábito sustentáveis que garanta atender a legislação ambiental e proporcione ganhos econômico, ambiental e social. Neste sentido o objetivo do trabalho foi verificar a influência da cultura organizacional na adoção da Produção Mais Limpa em uma empresa de beneficiamento de jeans no Agreste Pernambucano. Como Metodologia utilizou a técnica de pesquisa de campo com uso de questionário e entrevista. Os principais resultado leva ao entendimento que exista ausência de conhecimento da ferramenta $\mathrm{P}+\mathrm{L}$, ausência das variáveis socioambientais na identidade da empresa, espaço físico insalubre. Pode-se concluir que a cultura organizacional da lavanderia não influência positivamente para uma Produção Mais Limpa, uma vez que, na maioria de suas ações estiveram ausente as variáveis socioambientais como filosofia norteadora dos processos gerenciais e produtivo.

Palavras-Chave: Liderança, blue jeans, lavanderia têxtil, beneficiamento do jeans.

\section{Introdução}

A cultura organizacional pode ser entendida como importante variável para a prática da gestão ambientalmente sustentável, uma vez que, deve estar interligado os aspectos legais e a forma de gerenciar a empresa (Kaptein \& Wempe, 2002).

Segundo Barbieri et al. (2010), a sustentabilidade empresarial é um processo enfático que proporciona o alcance dos objetivos econômicos das organizações, sendo este o fator que determina a intensidade das práticas ambientais durante $\mathrm{o}$ processo produtivo $\mathrm{e}$ gerencial (Romano, 2014). Assim, a cultura organizacional vivenciada pode ser um determinante de sucesso ou fracasso da sustentabilidade ambiental (Baumgartner, 2009), ou seja, as mudanças organizacionais estão 
diretamente relacionadas aos aspectos culturais das empresas.

Hart \& Milstein (2004) afirmam que, a organização que internaliza a sustentabilidade como estratégia empresarial deve adaptar seus processos e políticas para gerar um produto sustentável a partir da minimização da poluição e o uso eficiente dos recursos naturais e artificiais.

Neste entendimento, o comprometimento ambiental em todos os elos da organização tornase um diferencial inovador para as organizações, vez que, a redução do impacto ambiental e o uso responsável dos recursos naturais estabelecem uma conciliação com crescimento econômico e desenvolvimento sustentável (Cavalcanti, 2012).

Segundo Silva, Souza \& Freitas (2012), quando a organização modifica seus processos, seja através de nova técnica de produção envolvendo sistemas ou mudança no processo, entende-se que houve uma inovação. Bebarba et al., (2016) corrobora ao acrescentar que inovação de processo visa à melhoria contínua da organização, na qual podem-se adotar métodos de mitigação aos danos ambientais além de contribuir com o bem-estar dos clientes internos e sociedade.

Neste sentido, as empresas precisam adotar estratégias sustentáveis permanentes visando o equilíbrio ambiental, respeito à sociedade, segurança e o bem-estar dos clientes internos e externos (Machado, 2014).

Portanto, as organizações que ainda não adotaram a sustentabilidade como norteadoras de suas ações precisam desenvolver uma nova cultura organizacional, mais focada na sustentabilidade. Deste modo a inovação voltada para a sustentabilidade empresarial compreende três tipos de mudanças: inovação tecnológica, social e organizacional (Rennings, 2000).

Neste contexto, Severo et al. (2012), afirmam que as empresas podem inovar seus processos através da adoção de sistemas de gestão ambiental como: Certificado ISO 14001, Sistema de Gestão de Resíduos (SGR), Análise do Ciclo de Vida (ACV), Estação de Tratamento de Efluentes (ETE), Produção Mais Limpa (P+L), Reciclagem, Simbiose Industrial (SI).

A adoção de um dos sistemas de gestão sustentável (SGR, ACV, ETE, P+L e SI) pode contribuir para a redução e eliminação dos impactos ambientais no entorno da organização. Debarba et al. (2016) afirmam que a inovação específica é um dos principais pilares da evolução da sociedade, da economia e das organizações. Assim, pode-se entender que a mudança organizacional não é fácil, pois existem diversas barreiras internas e externas que dificultam a adoção da inovação.
No entendimento de Lima, Silva \& Horostecki (2011), todas as empresas têm seus pontos em comuns, sendo apenas diferenciadas pela identidade organizacional que direcionam seus colaboradores aos objetivos almejados.

Neste sentindo, pode-se afirmar que um dos objetivos das empresas é a eficiência produtiva para atender cada vez mais seus clientes, o que tem resultado em desequilibro ambiental. Segundo Hosseini et al. (2016), os resíduos resultantes de diferentes processos industriais é uma constante preocupação do século XXI e exigem o uso de tecnologia limpa para garantir uma gestão ambiental equilibrada.

Uma das principais indústrias que tem contribuído com o desequilíbrio ambiental é o setor têxtil que utiliza grande quantidade de recursos. Assim os processos produtivos incluem a desengomagem, estonagem, secagem ou centrifugação, alvejamento, tingimento, neutralização, ensaboamento, amaciamento e passamento, o que necessita de tratamentos químicos e físicos (Itaborahy \& Silva, 2006).

Os processos têxteis em especial o beneficiamento tradicional do jeans é assunto que tem chamado atenção de pesquisadores, uma vez que, faz necessário o uso de 501: 920 galões de água, $400.000 \mathrm{KW}$ de energia, $32 \mathrm{~kg}$ de dióxido de carbono expelidos para a produção de uma calça de jeans (Figueiredo \& Cavalcante, 2010).

Uma das principais regiões produtora de jeans no Brasil é o Agreste Pernambucano, que concentra $16 \%$ da produção nacional do jeans (ABIT, 2018).

Essa produção tem contribuído para o crescimento econômico da região, mas, tem resultado em desequilíbrio ambiental, como afirma Lira (2009), as lavanderias têxteis, despejam os resíduos químicos utilizados no tratamento do jean nos rios Capibaribe e Ipojuca.

Corroborando, a Agencia Estadual de Meio Ambiente - CPRH afirma que as empresas de beneficiamento de jeans têm desempenhado um papel social importante, para o agreste pernambucano, em face das suas dinâmicas comerciais e geração de emprego e renda. Todavia, tem contribuído para o desequilíbrio ambiental ao promover poluição hídrica, atmosférica e do solo, visto seus processos produtivos, com efeito, a fase de beneficiamento do jeans (desengomagem, alvejamento, tingimento e amaciamento) modifica as característica naturais da água, pelo uso de corantes, sólidos suspensos, óleo e graxas, $\mathrm{pH}$ alterado, temperatura elevadas, concentrações significativas de matéria orgânica, presença de metais pesados e elevado teor de surfactantes (CPRH, 2018). 
Pode-se entender que o tradicional modelo de beneficiamento do jeans precisa encontrar alternativas mais sustentáveis que, segundo Figueiredo \& Cavalcante, (2010), essa produção é possível através da mudança de hábitos, uso de recursos sustentáveis, tecnologias que diminuam os níveis de produtos químicos, resíduos sólidos, líquidos e gasosos, água e energia.

Assim surgem a Produção Mais Limpa $\mathrm{P}+\mathrm{L}$ que tem como filosofia um modelo produtivo que atende a legislação ambiental, proporciona ganhos econômico e social. A aplicação das técnicas de $\mathrm{P}+\mathrm{L}$ tem apresentado êxito em várias indústrias em todo o mundo, em especial no setor têxtil, promovendo melhorias econômicas, organizacionais e ambientais (Silva et al., 2013).

Vale ressaltar que mais do que uma mudança tecnológica nas organizações, a $\mathrm{P}+\mathrm{L}$ trata de uma mudança organizacional, que envolve a cultura e o cotidiano das pessoas nas organizações (Fresner et al. 2010). Pois, quando a alta gestão e funcionários comprometem-se com a dimensão ambiental a $\mathrm{P}+\mathrm{L}$ poderá se tornar uma realidade (Silva Neto \& Jabbour, 2010).

Assim, o aprendizado da ferramenta $\mathrm{P}+\mathrm{L}$ deve ser colaborativo, compartilhado e interativo, objetivando que novos valores sejam criados, validados e tornem-se então parte da cultura organizacional da empresa (Van Hoff, 2014; Stone, 2006).

Para Silva, Todorov \& Silva (2012), as alterações culturas requerem mudanças cognitivas que relacionam às influências ambientais sobre as práticas produtivas. Neste sentido, a $\mathrm{P}+\mathrm{L}$ apresenta-se como possível alternativa para solucionar danos ambientais existentes nos entornos das indústrias de beneficiamento de denim, bem como, adequar os processos operacionais com as diretrizes dos órgãos de controle.

Objetivando o alinhamento das empresas de beneficiamento de jeans no agreste pernambucano com as normas ambientais, este estudo teve por objetivo verificar a influência da cultura organizacional na adoção da Produção Mais Limpa em uma empresa de beneficiamento de jeans no Agreste Pernambucano.

\section{Material e Métodos}

Este estudo é caracterizado como pesquisa de campo com enfoque exploratório e descritivo, que, segundo Gonçalves (2001), é o tipo de pesquisa que coleta os dados diretamente com a população do estudo, além de criar um banco de dados para consultas.

O estudo é caracterizado como descritivo com abordagem qualitativa, que tem a finalidade de compreender uma determinada problemática através do aprofundamento sobre as particularidades dos sujeitos participantes, buscando o entendimento do todo a partir das definições de cada participante (Diehl \& Tatim, 2004).

O questionário e a entrevista foram os instrumentos técnicos utilizados para levantar os dados da pesquisa que teve como sujeitos os gestores/gerentes de produção e/ou gerentes administrativos, abordando assuntos como: perfil da empresa, perfil dos funcionários, custo de produção, características dominantes da organização, liderança organizacional, a integração da organizacional, o clima organizacional, critérios de sucesso, estilo de gestão, tipo de cultura e o compromisso socioambiental.

As respostas do questionário foram organizadas através de uma escala tipo Likert que é composta por cinco variáveis, sendo a primeira 01 discordo totalmente da afirmação apresentada, 02 discordo parcialmente, 03 a afirmação é indiferente, 04 concorda parcialmente e 05 concorda totalmente com afirmação apresentada pelo pesquisador (Cunha, 2007).

As respostas dos participantes foram codificadas em um banco de dados e submetidas a técnicas analíticas de estatística descritiva com o objetivo de organizar os dados, permitindo dessa forma uma visão global da variação desses valores, a organização e compreensão dos dados foram realizadas por meio de tabelas e quadros

\section{Resultados e Discussão}

A empresa estudada é do segmento têxtil (lavanderia) e está localizada no Município de Toritama, Agreste do estado Pernambucano. Sua atuação no seguimento de lavanderia é de 15 anos em média, conta com 36 colaboradores, dos quais 30 atuam diretamente na produção, dois no administrativo, dois no design e dois na recepção das peças. Quanto ao gênero, $100 \%$ são colaboradores são do gênero masculino com idade que variam de 18 a 45 anos.

\section{A importância econômica de um modelo de produção Mais Limpa \\ $\mathrm{O}$ processo de beneficiamento do jeans} envolve o amaciamento das peças, o processo de lixamento, amassamento, polimento, detonação, entre outros.

A lavanderia realiza o beneficiamento médio mensal de 100 mil peças de jeans. Essa produção custa, segundo o proprietário, uma média de $\mathrm{R} \$ 117.000,00$ por mês, variando de acordo com a demanda. 
Como pode observar (tabela 1), o maior custo da produção está relacionado com pagamento dos funcionários, seguido dos produtos químicos e energia elétrica.

Tabela 1. Custo mensal do beneficiamento de 100 mil peças de jeans em uma lavanderia do município de Toritama- PE em 2019. Fonte: Silva \& Menelau (2019).

\begin{tabular}{lr}
\hline Despesa Mês & \multicolumn{1}{l}{$\begin{array}{l}\text { Valor } \\
\text { mês }\end{array}$} \\
\hline Funcionários & $45.000,00$ \\
Compra de Água & $5.280,00$ \\
Tratamento da Estação de água & 500,00 \\
Compra de madeira $\left(88 \mathrm{~m}^{2}\right)$ & $2.200,00$ \\
Consumo de energia & $15.000,00$ \\
Produtos químicos & $35.000,00$ \\
Recolhimento dos Resíduos (9 & $2.000,00$ \\
toneladas de lodo) & \\
Aluguel & $2.000,00$ \\
Custo com o escritório (papelaria, & \\
produtos de higiene e copa) & $10.000,00$ \\
Custo total: & $116.980,0$ \\
& 0 \\
\hline
\end{tabular}

De acordo os dados coletados (Tabela 1), a lavanderia investe $\mathrm{R} \$ 5.280,00$ reais mensais em compra de água (88 carros pipas de 15 mil litros cada), não obstante, reutilizar cerca de $60 \%$ do volume de água nos processos de beneficiamento, como pode ser observado na fala do gestor:

Durante o processo de lavagem pedese muita água e não dá para aproveitar mais de $60 \%$ da água. $O$ processo de tratamento dos efluentes demora mais de três dias e quando a demanda é grande compramos mais água de carro pipa... Também precisamos de uma média de 70 litros de água para lavar uma peça (Gestor, 2019).

Como pode-se observar, para atender a produção mensal a empresa precisa de 7 milhões de litros de água (70 litros por peças vezes $100 \mathrm{mil}$ peças). Também foi observada que ela reutiliza $60 \%$ da água do processo produtivo, o que representa uma economia de 4 milhões de litros por mês (60\% de 7 milhões), o que leva a economia de média 16 mil reais mensais (para comprar 1.320.000 litros de água custa $\mathrm{R} \$ 5.280,00$ para comprar 4 milhões é necessário R \$ 16.000,00).

Com a reutilização de água mensal e com um custo de tratamento de $\mathrm{R} \$ 500,00$ reais podese afirmar que a empresa economiza $\mathrm{R} \$ 15.500,00$ reais com o reuso de $60 \%$ de água.

Vale destacar que a preocupação do gestor quanto a reutilização da água está relacionada apenas com as questões financeiras. Assim, podese afirmar que uma organização sustentável é aquela que mantem em equilíbrio as variáveis sociais, ambientais e econômica.

Também pode-se identificar que existe um desperdício de $40 \%$ do volume de água utilizado no processo produtivo, o que leva ao entendimento que existe uma ineficiência, ou seja, prejuízo financeiro e ações não sustentável. Assim, quanto maior a eficiência no uso da matéria-prima, maior a economia e maior será a interação com o método da $\mathrm{P}+\mathrm{L}$.

Segundo Silva et al. (2013), a P+L tem apresentado êxito em várias indústrias em todo o mundo, em especial no setor têxtil, promovendo melhorias econômicas, organizacionais e ambientais.

A principal fonte enérgica da empresa é a energia elétrica, (ausência de energias renováveis, exceto a madeira que é utilizada nas caldeiras que abastecem os ferros de passar e a máquina de centrifugar).

Nossa produção utiliza uma lenha de origem exótica e de reflorestamento (algaroba) além de utilizamos na chaminé da caldeira, filtros que impede que a fuligem proveniente da queima da lenha vá para atmosfera (fala do Gerente de produção, 2019).

Diante da fala do gerente, percebe-se que a empresa atende a uma das normas da CPRH (utilização de filtros nas caldeiras) e do IBAMA (uso de lenha da espécie exótica), o que se entende como elementos positivos para a gestão ambiental da empresa, além de contribuir para a não geração de multa e advertências, que segundo o CNTL (2003) a P+L versa sobre uma produção que atende as normas ambientais.

Durante a visita, foi possível observar o uso de IPIs por todos os funcionários, iluminação natural, ventilação através das janelas, exautores, cortinas d'agua. Mas não foi possível identificar se às leis trabalhistas estavam sendo cumpridas, uma vez que, os respondentes não disponibilizaram o acesso as informações como: FGTS, Férias, INSS, horas extras, salários, entre outros.

Quanto ao maquinário, os gerentes afirmaram que a troca de um equipamento só é realizada de acordo com as condições financeiras e necessidades de atender a demanda, e que a manutenção é realizada por funcionários próprios. O que leva a entender que não exista uma manutenção preventiva, requisito importante para trabalhar com o método P+L (CNTL, 2003).

Para atender a "moda" (o design solicitado pelos clientes) o gerente de produção relata que 
muitas das técnicas usadas são criadas pelos próprios funcionários, inspiradas nas redes sociais.

Assim, criaram produtos/instrumentos que auxiliam na eficiência do serviço diário, um exemplo é o manequim inflável que recebe a quantidade de ar de acordo com a peça, esse processo acontece durante o lixamento das peças jeans, para deixa-la com aspecto desgastado.
Análise do processo produtivo a partir do método de Produção Mais Limpa

Quanto ao reuso da água e tratamento dos efluentes, percebe-se que a empresa ainda está voltada para o tratamento de fim de tubo (preocupado em tratar em vez de prevenir a geração de efluentes e consequentes danos ambientais), que pode ser constatado pelo processo de entrada e saída da matéria-prima, conforme consta no quadro 1.

Quadro 1. Análise da entrada e saída da matéria-prima no processo de beneficiamento do jeans em uma lavanderia do município de Toritama Pernambuco. Fonte: Silva \& Menelau, (2019).

\begin{tabular}{|l|l|l|l|}
\hline Entrada & Processo & Saída \\
\hline $\begin{array}{l}\text { Insumo } \\
\text { (entrada) }\end{array}$ & Origem & Etapas da produção & $\begin{array}{l}\text { Resultado do } \\
\text { beneficiamento (saída) }\end{array}$ \\
\hline $\begin{array}{l}\text { Água não } \\
\text { tratada }\end{array}$ & $\begin{array}{l}\text { Carro bipa (Rio } \\
\text { Capibaribe) }\end{array}$ & $\begin{array}{l}\text { Uso em todos os processos de } \\
\text { lavagem e enxague }\end{array}$ & Efluentes líquidos \\
\hline Água tratada & Compesa & $\begin{array}{l}\text { Caldeira (vapor para passar ferro } \\
\text { e energia para mover a máquina } \\
\text { de centrifugação) }\end{array}$ & $\begin{array}{l}\text { Calor no interior da } \\
\text { empresa }\end{array}$ \\
\hline Energia & Celpe & $\begin{array}{l}\text { Máquinas produtivas, escritório, } \\
\text { iluminação da indústria. }\end{array}$ & Aquecimento \\
\hline Madeira & $\begin{array}{l}\text { Algaroba (compra } \\
\text { com nota) }\end{array}$ & Caldeira & $\begin{array}{l}\text { Resíduos gasosos, fumaça, } \\
\text { cinza. }\end{array}$ \\
\hline $\begin{array}{l}\text { Produtos } \\
\text { químicos }\end{array}$ & $\begin{array}{l}\text { Empresas } \\
\text { especializadas }\end{array}$ & $\begin{array}{l}\text { Lavagem, amaciamento, } \\
\text { descolorimento. }\end{array}$ & $\begin{array}{l}\text { Resíduos sólidos (lodo) e } \\
\text { líquidos contaminados do } \\
\text { solo e da água }\end{array}$ \\
\hline Lixas e matérias & Empresas locais & Lixamento da peça jeans & $\begin{array}{l}\text { Pó de produtos químico e } \\
\text { tecido }\end{array}$ \\
\hline
\end{tabular}

De acordo com as informações do quadro 1 , verifica-se que, os insumos são transformados em resíduos líquidos, sólidos e gasosos, os quais recebem o tratamento após sua geração.

Quanto à destinação dos efluentes, constatou-se que o lodo é destinado ao aterro sanitário do município de Caruaru (Toritama não disponibiliza de aterro sanitário), a água tratada após uso (60\%) volta para os tanques de armazenamento para ser reutilizadas no processo produtivo.

Quanto ao nível de $\mathrm{P}+\mathrm{L}$, constatou-se que a lavanderia não consegue evitar a geração de efluente, cujo volume está totalmente ligado à quantidade de peças produzidas, e quanto à água, principal matéria-prima, é feita a reciclagem interna, reintegrando água ao processo de produção que caracteriza a empresa no nível 2 da $\mathrm{P}+\mathrm{L}$, ou seja, existe a reciclagem interna da principal matéria-prima, a água, o que atende os parâmetros do CNTL (2003).

Constatou-se, ainda, que a empresa realiza o tratamento do efluente têxtil (água contaminada com grande quantidade de produtos químicos, após uso na lavanderia) e que segundo seus responsáveis o tratamento de efluentes na lavanderia é do tipo físico-químico por coagulação floculação e decantação, conforme Figura1.

A remoção da carga orgânica é de $70 \%$, clareando a cor da água, permitindo a reutilização da água tratada apenas na fase de lavagem, visto que, as caldeiras precisam de água com um $\mathrm{pH}$ entre 7 e 10 , e na fase de enxágue precisam da água com um pH entre 6 e 8.

As etapas do tratamento dos efluentes líquidos da lavanderia percorre sete etapas, até ficar disponível para reuso, conforme pode ser observado na Figura 1. 


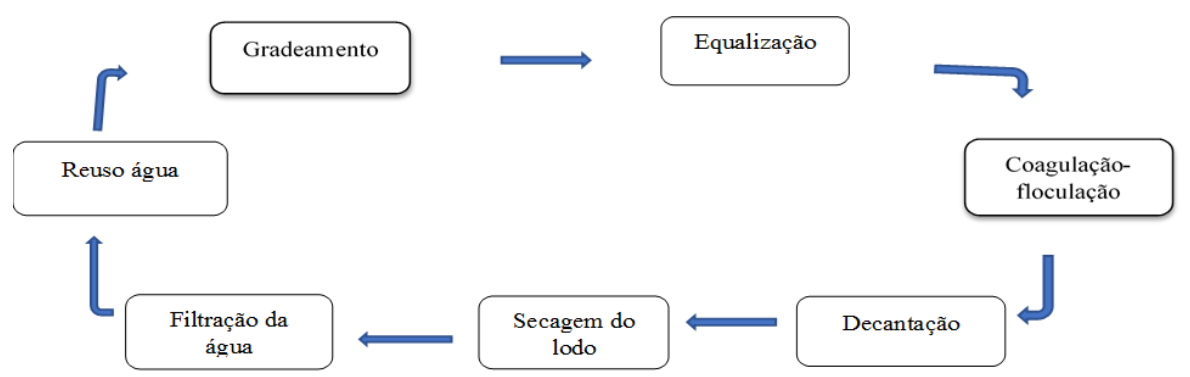

Figura 1. Etapas do tratamento de efluentes em uma lavanderia do município de Toritama - PE, no ano de 2019. Fonte: Silva \& Menelau (2019).

De acordo com a Figura 1, o tratamento dos efluentes líquidos da lavanderia estudada passa pelos processos de gradeamento, equalização, coagulação floculação, decantação, secagem do lodo, filtração da água e volta para o processo produtivo o que necessita no mínimo, três dias para considerar a água para uso. formas:

Os processos são realizados das seguintes

- Gradeamento: remoção de sólidos grosseiros (fibras de jeans) utiliza areia;

- Equalização: uniformização das diferentes descargas de efluentes e correção do pH usa produtos químicos (max panc flok);

- Coagulação-floculação: adição de sais metálicos (policloreto de alumínio, sulfato de alumínio) e de polímeros catiônicos em algumas situações, para a formação de flocos decantáveis, realizando a eliminação do material suspenso e coloidal, removendo a cor e a turbidez.

- Decantação: deposição dos flocos formados na coagulação floculação

- Secagem do lodo: redução da umidade do lodo industrial, formado na decantação para seu descarte adequado (a cada 45 dias são recolhidos para o aterro sanitário, devidamente regulamentado pela $\mathrm{CPRH}$ ).

- Filtração da água: remoção dos flocos remanescentes no efluente tratado.

- Reuso da água no processo de beneficiamento das peças jeans a lavanderia consegue reaproveitar em média $60 \%$ da água utilizada, o que também representa uma economia de $60 \%$ da compra de água.

- Todos os processos são realizados por um funcionário responsável e supervisionado pelo gerente de produção que é responsável de coletar amostra da água tratada e enviar ao laboratório credenciado na associação das lavanderias têxteis de Toritama.

Vale ressaltar que, a $\mathrm{P}+\mathrm{L}$ é um modelo contínuo e com isso faz necessário que todas as ações da organização seja planejada de modo que atenda as questões sociais, ambientais e econômica, bem como, seu foco deve está voltado para uma produção sustentável que tem como resultado a economia financeira, boa imagem da organização perante a sociedade e atendimento as legislações trabalhistas, ambientais e fiscais.

\section{Cultura organizacional da empresa e a Produção Mais Limpa}

A identidade organizacional tem como objetivo nortear as ações da empresa. Neste contexto, a primeira pergunta da entrevista esteve relacionada com a definição da identidade organizacional da empresa. Por sua vez. o proprietário afirmou que não tem nenhum documento, quadro ou meios digitais, mas a empresa é regida por valores como respeito, qualidade e agilidade, quanto à visão o proprietário afirma que o foco é capitar mais cliente nos próximos anos, e sua missão é ser referência no seguimento de beneficiamento de jeans na região.

Pode-se identificar que a identidade organizacional existe de forma empírica, também pode-se identificar durante a entrevista que o proprietário não citou as variáveis ambientais e sociais e a sustentabilidade ambiental como item dos valores organizacionais.

É importante salientar que, as empresas que têm a responsabilidade socioambiental como valores norteadores de suas ações tornam as barreiras ambientais mais fáceis de serem sanados.

Neste sentido, pode-se afirmar que a comunicação dentro da organização, na qual pessoas diferentes, guiadas pela mesma cultura organizacional, possam interagir buscando um resultado comum, o que contribuirá para o sucesso da responsabilidade socioambiental da empresa.

Uma das formas para se chegar nesse sucesso é o fortalecimento dos valores organizacionais, seja por meio de treinamentos, avaliações e, obviamente, fazendo com que os funcionários se sintam como partes integrantes dos resultados da empresa.

O estudo de Pinsky \& Kruglianskas (2017) evidenciou que as barreiras internas versam sobre a carência de infraestrutura das organizações, os arranjos organizacionais, educação, profissionais qualificados, procedimentos rigorosos, 
conservadorismo, estruturas de comunicação formal e hierárquica, conformidade, falha de visão, legislação vigente, carga tributária e oposição à mudança.

A partir da percepção dos pesquisadores o proprietário foi indagado sobre a postura dos clientes quanto às questões ambientais:

Nossos clientes estão preocupados em pagar menos pelo serviço.... Não quer saber como foi realizado o processo... Nunca nos questionários sobre meio ambiente (fala do Proprietário da lavanderia 2019).

Diante da fala do proprietário pode-se perceber que o fato dos clientes não terem questionado sobre questões ambientais, não foi considerado importante para a estratégia da organização. O estudo de Pinsky \& Kruglianskas, (2017) ressalta a importância da comunicação, e acrescenta que os rigorosos procedimentos, estruturas de comunicação formal e hierárquica, tradicionalismo, consonância, oposição à mudança falha de aparição e falta de comprometimento com o meio ambiente são sem dúvidas barreiras para uma cultura organizacional focada no método $\mathrm{P}+\mathrm{L}$.
Seguindo a entrevista, o proprietário foi indagado sobre conhecer à Produção Mais Limpa:

Para mim esse nome é novo, não conheço sua função, e para ser sincero estou conhecendo a partir dessa entrevista (Gestor, 2019).

Pode-se afirmar que a Produção Mais Limpa é um tema novo, o que também justifica o desconhecimento por parte da gestão da empresa, como afirma o CNTL (2003), o desconhecimento da ferramenta $\mathrm{P}+\mathrm{L}$ pode ser um fator de insucesso para as empresas que precisam adotar $\mathrm{P}+\mathrm{L}$. No estudo de Vieira \& Amaral (2016), foi possível identificar que as empresas apresentam dificuldade quanto à compreensão do conceito da $\mathrm{P}+\mathrm{L}$ e à educação ambiental.

A Cultura organizacional da empresa em estudo tem como característica dominante a formalidade através dos processos burocráticos (ver tabela 2).

Segundo Melo (2012), a cultura burocrática está centrada nas regras estabelecidas, ordem, hierarquia, segurança e formalismo, sua ênfase está voltada para a orientação e controle interno.

Tabela 2. Cultura organizacional predominante da lavanderia estudada. Fonte: Silva \& Menelau (2019).

\begin{tabular}{|l|l|}
\hline Cultura organizacional & Cultura da empresa \\
\hline $\begin{array}{l}\text { Características dominantes da } \\
\text { organização }\end{array}$ & $\begin{array}{l}\text { O proprietário detém todo o poder de decisão, todos os funcionários } \\
\text { seguem as diretrizes estabelecidas pelo os mesmos. }\end{array}$ \\
\hline Liderança organizacional & O foco é a produção e não as pessoas. \\
\hline A integração organizacional & $\begin{array}{l}\text { Produzir para atender a demanda de acordo com as metas diárias } \\
\text { (peças/clientes) }\end{array}$ \\
\hline O clima organizacional & $\begin{array}{l}\text { Os colaboradores vivem sobre exigências de cumprimentos de metas de } \\
\text { produção (clima tenso). }\end{array}$ \\
\hline Critérios de sucesso & $\begin{array}{l}\text { Sucesso é atender os clientes com o menor preço, competitividade através } \\
\text { do preço. }\end{array}$ \\
\hline Estilo de gestão & É caracterizado pela produtividade diária e competitividade pelo preço. \\
\hline Tipo de cultura & $\begin{array}{l}\text { Concentram a liderança apenas no proprietário que definem todas as } \\
\text { decisões das organizações. }\end{array}$ \\
\hline
\end{tabular}

De acordo com os dados da pesquisa (ver Tabela 2), a liderança organizacional é considerada exigente, agressiva e competitiva uma vez que, o foco é voltado para a produção e não as pessoas, o que torna a empresa insustentável, ou seja, as ações do âmbito social não são atendidas.

A liderança se aproxima do tipo autocrático que, segundo Davis \& Newstron (2002), este tipo de líder é mais conhecido como "chefe" é ele que define o que deve ser feito e sua opinião é sempre a mais correta e não deposita a confiança em seus subordinados.

O clima organizacional predominante da organização é a competitividade e a agressividade, tendo como objetivo competir através do menor preço, ou seja, não existe a variável socioambiental como estratégia competitiva.

Os colaboradores vivem sobre exigências de cumprimentos de metas de produção diária (clima tenso).

O critério de sucesso da organização é definido com base numa filosofia de menor preço, assim, o sucesso é conseguir atender os clientes com o menor preço, competindo com os concorrentes através do preço, ou seja, não existe critérios socioambientais como variáveis de sucesso para a organização em estudo. 
O Estilo de gestão é caracterizado pela exigência, produtividade e competitividade.

Quanto à liderança (tabela 2), a empresa concentra a liderança em uma única pessoa, o proprietário, mesmo disponibilizando de dois gerentes. Assim todas as decisões são tomadas de acordo com seu ponto de vista e conhecimento.

Tal cultura organizacional pode ser entendida, de acordo com Ribeiro et al. (2005), como uma barreiras para a ocorrência da $\mathrm{P}+\mathrm{L}$ nas lavanderias têxteis, vale ressalta que segundo o mesmo estudo, este fenômeno pode estar relacionado com ausência de conhecimento e métodos sustentáveis, clima motivacional desfavorável, deficiências na qualidade de vida no trabalho e dificuldades com novas tecnologias, além da falta de conhecimento ao classificar e dividir os seus resíduos em recicláveis ou não recicláveis, bem como a não valorização do meio ambiente por diversos colaboradores das organizações.
Portanto, pode-se classificar a cultura da empresa como a cultura do poder onde os colaboradores são inteiramente orientados a conquistar resultados, também se pode entender que esse tipo de cultura é mais comum em empresas pequenas principalmente por não consentirem o crescimento e desenvolvimento das capacidades de seu capital humano (Davis \& Newstron, 2002).

\section{Comprometimentos socioambientais da empresa analisada (lavanderia)}

Para obter os dados relacionados com o comprometimento socioambiental, utilizou-se uma escala com cinco frequências, onde as respostas dos três respondentes foram centradas entre as três primeiras frequências (discordo totalmente, discordo parcialmente e indiferente com as afirmativas), como pode ser observado nas Figuras 2 e 3.

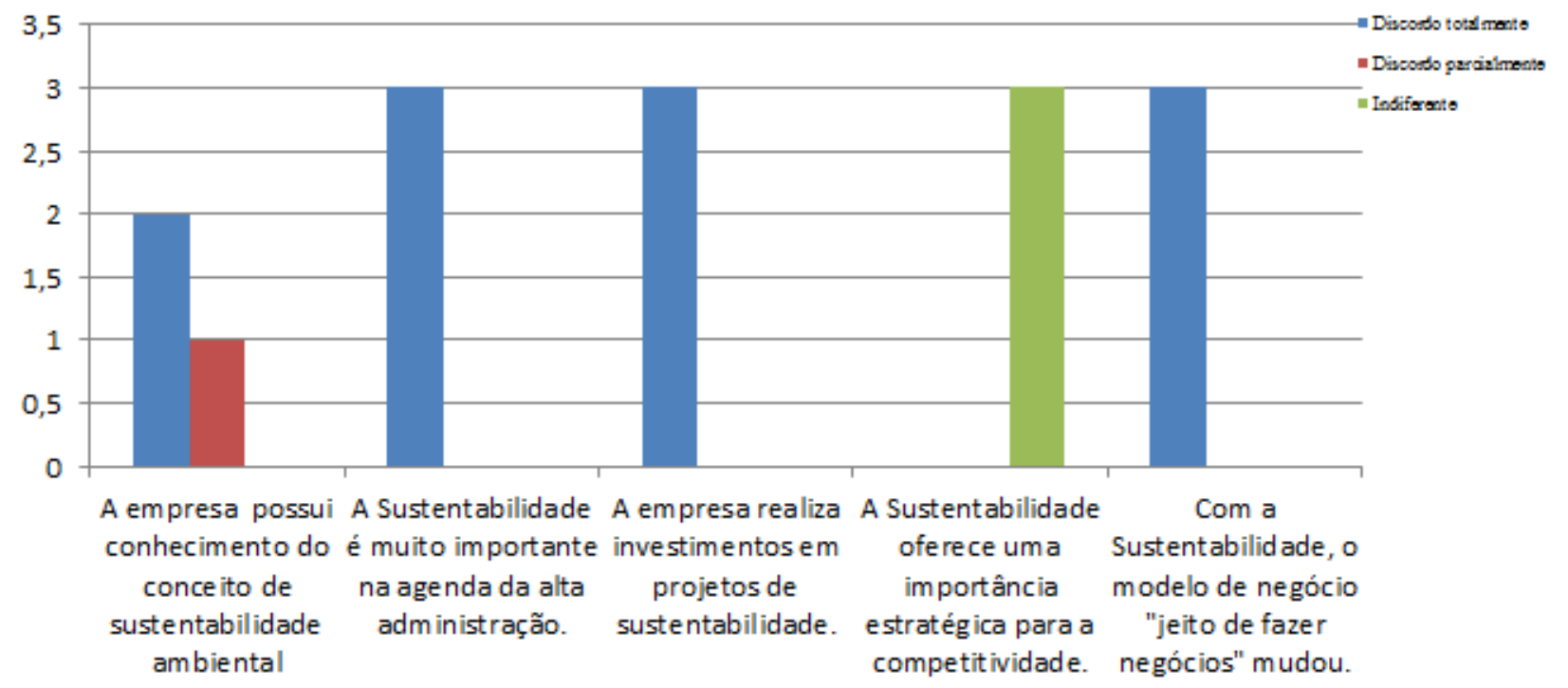

Figura 2. Compromisso socioambiental de uma lavanderia do município de Toritama - PE, no ano de 2019. Fonte: Silva \& Menelau (2019).

De acordo com os dados (gráfico 1), podese entender que a variável ambiental não foi contemplada como importante na agenda da alta administração, tendo em vista a não realização de projetos na área, e que a filosofia da empresa é voltada para atender a demanda do cliente baseada no preço baixo. Assim, o jeito de fazer o negócio não está pautado para atingir um desenvolvimento sustentável.

O desconhecimento dos entrevistados sobre sustentabilidade ambiental pode estar contribuindo para ausência do comprometimento de uma produção eco sustentável.

No quesito estratégia empresarial a partir de uma produção ambientalmente correta, ou seja, uma produção que atende as questões sociais, ambientais e econômica, os entrevistados responderam que essa temática era indiferente para a competitividade da organização.

Sobre a comunicação da organização observou-se (ver gráfico 03), que os gestores da empresa não comunicam (interna e externamente) os esforços e compromissos de sustentabilidade ambiental.

No que se refere à prática de combate à poluição durante o processo produtivo, dois dos respondentes afirmaram concordar, em parte, que a empresa tenha pratica de combater a poluição, pois a empresa utiliza filtro na caldeira, trata os efluentes e reusa a água. 


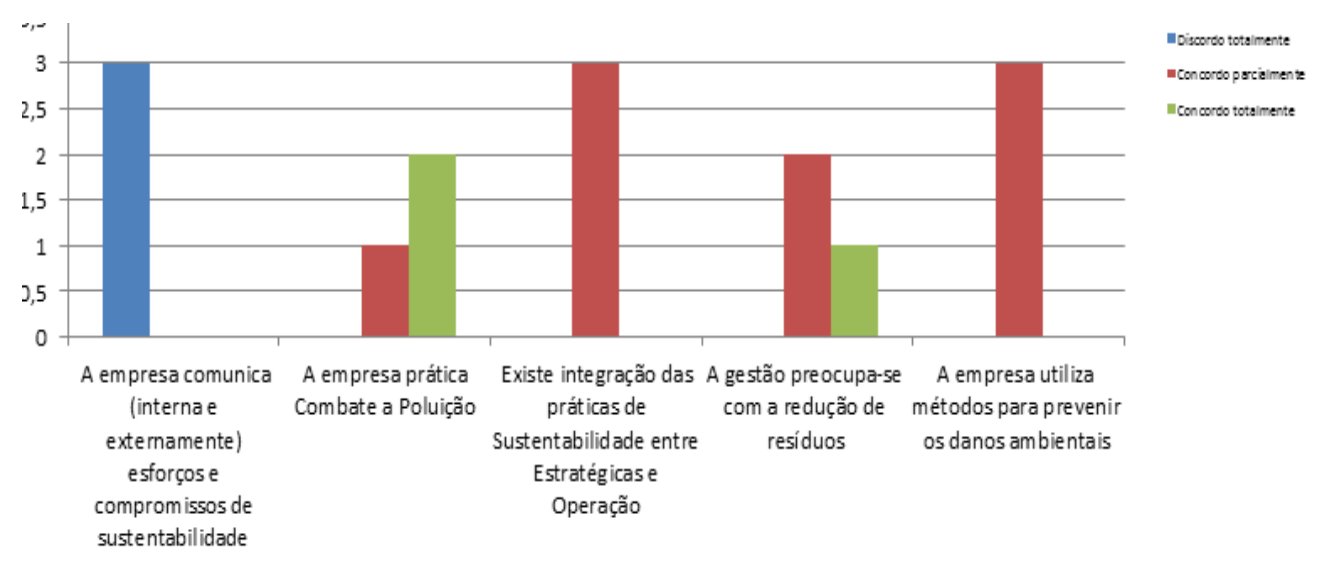

Figura 3. Método de Produção Mais Limpa em uma lavanderia do município de Toritama - PE, no ano de 2019. Fonte: Silva \& Menelau (2019).

Pode-se observar (Figura 3), que os respondentes concordam parcialmente que exista integração das práticas de sustentabilidade entre estratégicas e operação na organização.

Quanto à preocupação da gestão com a redução de resíduos, dois responderam que concordam totalmente e um que concorda parcialmente. Quanto aos métodos utilizados pela empresa para prevenir os danos ambientais, todos os respondentes concordam parcialmente com essa afirmativa.

Por tanto, como principais resultados pode-se afirmar que existem ausência de conhecimento da ferramenta $\mathrm{P}+\mathrm{L}$, ausência das variáveis socioambientais na identidade da empresa.

O foco da empresa está voltado para produção e não as etapas do processo, outro ponto identificado foi ausência de projetos e ações socioambientais.

Também pode-se entender que os resultados do beneficiamento do jeans na lavanderia estudada, proporciona uma grande quantidade de resíduos líquidos, sólidos e gasosos, onde seu tratamento é no final do processo produtivo.

A área física da empresa pode ser classificada em insalubre devido à grande área molhada e de calor intenso.

Como limitação do estudo, pode-se afirmar que o envolvimento do proprietário com todas as tarefas da organização limitou a responder o questionário e conceder a entrevista nos primeiros contatos, assim para coletar os dados o pesquisador fez várias visitas em dias diferentes.

\section{Considerações finais}

A $\mathrm{P}+\mathrm{L}$ é um modelo produtivo que versa sobre uma mudança na cultura organizacional da empresa através de hábito sustentáveis que garanta atender a legislação ambiental e proporcionar ganhos econômico, ambiental e social.

Este estudo teve como objetivo verificar a influência da cultura organizacional na adoção da Produção Mais Limpa em uma empresa de beneficiamento de jeans no Agreste Pernambucano. Para responder ao objetivo da pesquisa utilizou o método de estudo de campo.

A cultura organizacional da empresa, é centralizadora e está voltada em atender resultados (demanda do cliente), e atender as normas ambientais estabelecidas pelos órgãos de fiscalização e a lei dos resíduos sólidos (tratar e destinar os resíduos após sua geração).

Neste entendimento, pode-se afirmar que a cultura organizacional da lavanderia não contempla uma produção ambientalmente correta, uma vez que, na maioria de suas ações estiveram ausente as variáveis ambientais como filosofia norteadora, além de ausência dos valores socioambiental na identidade organizacional da empresa.

Assim, pode-se entender que a influência da cultura organizacional a partir do atual sistema empresarial contribui negativamente para o sucesso de um modelo de Produção Mais Limpa.

As fragilidades como ausência de preocupação ambiental, conhecer a $\mathrm{P}+\mathrm{L}$, divisão da tarefa, planejamento de processo, tratamento dos resíduos durante o processo produtivo, entre outros, mostra que a cultura organizacional vivenciada pela empresa se mostra inviável adoção do modelo $\mathrm{P}+\mathrm{L}$.

Vale salientar, que para atuar conforme a ferramenta $\mathrm{P}+\mathrm{L}$ a empresa precisa seguir alguns padrões como: produção planejada com foco no desperdício zero, dividir as tarefas com os colaboradores, focar nas questões de prevenção ambiental como norteadora da filosofia da empresa. Além de contemplar as variáveis sociais, 
ambientais e econômica de forma equilibrada em todas as ações da empresa.

Como pesquisa futura, recomenda-se um estudo mais aprofundados dos processos organizacionais em comparação com o modelo $\mathrm{P}+\mathrm{L}$

Portanto, para o sucesso na adoção da Produção Mais Limpa impõe-se uma mudança cultural onde ocorram quebras de paradigmas, uma vez que a $\mathrm{P}+\mathrm{L}$ é mais do que um instrumento, é uma nova configuração de produzir de forma responsável preocupando-se com as próximas gerações.

\section{Agradecimentos}

À Coordenação de Aperfeiçoamento de Pessoal de Nível Superior-CAPES pelo apoio financeiro e a Coordenação do Programa PósGraduação em Administração e Desenvolvimento Rural-PADR.

\section{Referências}

Araújo, M.; Castro, E. M. M. 1999. Manual de Engenharia Têxtil. Lisboa: Fundação Calouste Gulbenkian. 694p.

Barbieri, J. C.; Vasconcelos, I. F. G.; Andreassi, T.; Vasconcelos, F. C. 2010. Inovação e sustentabilidade: novos modelos e proposições. Revista de Administração de Empresas, 50, (2), 146-154.

Baumgartner, R. J. 2009. Organizational culture and leadership: preconditions for the development of a sustainable corporation. Sustainable Development, 7, 102-113.

Chiavenato. I. 2012. Gestão de pessoas. ( $4^{\mathrm{a}} \mathrm{ed}$. Rio de Janeiro: Elsevier. 512p.

Cavalcanti, S. L. O. 2012. Contabilidade ambiental e desenvolvimento sustentável: um estudo nas empresas de panificação de Campina Grande - PB. Monografia (graduação) curso de ciências contábeis, Universidade Estadual da Paraíba, 25p.

CNTL- Centro Nacional de Tecnologias Limpas 2003. Implementação de programas de Produção Mais Limpa. Apostila. Porto Alegre. 46p.

CPRH - Agência Estadual de Meio Ambiente 2018. Lavando limpo. Disponível em: emhttp://www.cprh.pe.gov.br/ARQUIVOS_ ANEXO/cartilha\%20lavando\%20limpo; 4901; 20181211. Pdf. Acesso em 16 junho 2019.

Cunha, L. M. A. 2007. Modelos Rasch e Escalas de Likert e Thurstone na medição de atitudes. Dissertação de Mestrado, Universidade de Lisboa Faculdade de Ciências. Departamento de Estatística e Investigação Operacional. Lisboa Portugal. 78p.

Hosseini H.; Ghorbani, M.; Meshginfar, N.; Mahoonak, A.S. 2016. A Review on Frying: Procedure, Fat, Deterioration Progress and Health Hazards. Journal of the American Oil Chemists' Society, 93, (4), 445-466.

Davis, K.; Newstrom, J. W. (2002), Comportamento humano no trabalho: uma abordagem psicológica. São Paulo: Pioneira. $207 p$.

Debarba, J. G.; Severo, E. A. Girardi, G.; Capitania, R. P. R. 2016. Inovação de processo e sustentabilidade em uma indústria metalomecânica. In: II Simpósio Internacional de Inovação em Cadeias Produtivas do Agronegócio (SICPA). Disponivel em: http://www.ucs.br/etc/conferencias/index.ph p/IIsimposioinovacaoagronegocio/simposioi novacaoagronegocioucs/paper/viewFile/460 0/1446. Acesso em: 25 set. 2019.

Diehl, A. A; Tatim, D. C. Pesquisa em ciências aplicadas: métodos e técnicas. São Paulo: Prentice Hall, 2004. 168p.

Dunphy, D.; Griffths, A.; Benn, S. Organizational change for Corporate Sustainability. A guide for leaders and change agentes of the future, $2^{\circ}$ ed. Rontlege, Taylor \& Francis Group|, 2007. Disponível em: http://www.sustenn.com/files/user_files/25_ Frederic_Laloux/dunphyorganizationalchange-for-corporatesustainability.pdf. Acesso em: 10 jan. 2019.

Epstein, M. J. 2008. Making sustainability work: best practices in managing and measuring social and environmental impacts. Sheffield: Greenleaf Pub. San Francisco: BerrettKoehler Publishers, Edition: 288p.

Figueiredo, G. C.; Cavalcante, 2010. A. L. B. L. Calça Jeans Produtividade e Possibilidades Sustentáveis. Revista Projética Londrina, 1, (1), 128-145.

Fresner, J.; Jantschgi, J., Birkel, S., BärnthaleR, J.; Krenn, C. 2010. A teoria da solução criativa de problemas (TRIZ) como ferramenta de geração de opções em projetos de produção mais limpa. Jornal de Produção Mais Limpa, $18,(2), 128-136$.

Gonçalves, E. P. 2001. Iniciação à pesquisa científica. Campinas, SP: Editora Alínea. 80p.

Hart, S. L.; Milstein, M. B. 2004. Criando valor sustentável. RAE Executivo, 3, (2), 65-79.

Itaborahy, M. A; Silva, V. H. 2006. Indústrias de confecção no município de Cianorte/PR e a necessidade de implantação de programas de 
Gestão Ambiental. Revista Ciências Empresariais, 12, (1), 360-387.

Kaptein, M.; Wempe, J. 2002. The balanced company: a theory of corporate integrity. Oxford: Oxford University Press, p. 360.

Lima, L; Silva, L. E. P.; Horostecki, M. F. 2011. Cultura Organizacional. Anais, VIII SEGeT Simpósio de inovação tecnológica. Resende/RJ. p. 12.

Lira, Sonia Maria de (2009). O "desenvolvimento" do aglomerado de micro e pequenas indústrias de confecções do Agreste/PE: as suas inter-relações socioespaciais. Tese (doutorado) - Universidade Federal de Pernambuco. Recife, Pernambuco. 214p.

Machado, C. M. 2014. Tecnologia da informação aplicada à gestão da responsabilidade social. In: Congresso nacional de excelência em gestão - CNEG. Rio de Janeiro e Niterói. pp. 1446-1462.

Mattar, F. N. 2005. Pesquisa de marketing. 5. ed. São Paulo: Atlas. 275p.

Pinsky, V.; Kruglianskas, I. 2017. Inovação tecnológica para a sustentabilidade: aprendizados de sucessos e fracassos. Revista Estudos Avançados, 31, (90), 107-126.

Rennings, K. 2000. Redefining Innovation: Ecoinnovation Research and the Contribution from Ecological Economics. Ecological Economics, 32, (2), 319-32.

Ribeiro, L. A.; Bressan, L. W.; Lemos, M. F.; Dutra, C.; Nascimento, L. F. 2005. Avaliação de barreiras para implementação de um sistema de gestão ambiental na UFRGS. XXV Encontro Nac. de Eng. de Produção - Porto Alegre, RS. Disponível em: http://www.abepro.org.br/biblioteca/enegep2 005_enegep1002_1755.pdf. Acesso em: 25 set. 2019.

Romano et al. 2011. Investimento em Sustentabilidade Corporativa versus retorno financeiro: Abordagem integrada, VII Congresso Brasileiro de Sistemas - Franca, SP, Brasil. Disponível em: http://www2.facef.br/ocs/index.php/CBS/7C BS. Acesso em: 04 mar. 2019.

Romano, A. L. 2014. Proposta de modelo de avaliação da sustentabilidade corporativa: as práticas no setor de cosmético brasileiro Tese de doutorado apresentada ao Programa de Pós-Graduação em Engenharia de Produção da Universidade Metodista de Piracicaba. Santa Bárbara D'Oeste-São Paulo.

Santos, E. M.; Oliveira Neto, J. D.; Barbosa, D. H.; Yamanaka, L. 2006. Produção Mais Limpa: elementos para discussão e análise. Anais. ADM2006 $19^{\circ}$ Congresso Internacional de Administração Ponta Grossa, Paraná, Brasil.

Severo, E. A.; Dorion, E.; Olea, P. M.; Camargo, M. E.; Nodari, C. H.; Cruz, M. R. 2012. Cleaner Production: Cases of the MetalMechanic Automotive Cluster of Serra Gaucha, Brazil. African Journal of Business Management, 6, 10232-10237.

Silva, D. A.L; Delai, I.; Castro, M. A. S; Ometto, A. R.2013. Quality tools applied to Cleaner Production programs: a first approach toward a new methodology. Journal of Cleaner Production, 47, 174- 187.

Silva, A.V; Todorov, J. C.; Silva, R. L. F. C. 2012. Cultura organizacional: a visão da análise do comportamento. Revista Brasileira Terapia e Comportamento cognitivo, 14, (2), 48-63.

Silva, M. E; Sousa, I G; Freitas, L S. 2012. Processo de inovação: um estudo no setor moveleiro de Campina Grande-PB. RAI: Revista de administração e inovação, Brasil, 9, (1), 257-279.

Silva Neto, A.; Jabbour, C. J. C. 2010. Guidelines for improving the adoption of cleaner production in companies through attention to non-technical factors: A literature review. African Journal of Business Management, 4, (19), 4217-4229.

Van Hoof, B. 2014. Organizational learning in cleaner production among Mexican supply networks. Journal of Cleaner Production, 64, 115-124.

Stone, L. J. 2006. Limitations of cleaner production programmes as organisational change agents I. Achieving commitment and on-going improvement. Journal of Cleaner Production, 14, (1), 1-14.

Vieira, L. C.; Amaral, F. G. 2016. Barriers and strategies applying Cleaner Production: a systematic review. Journal of Cleaner Production, 113, (1), 5-16. 